\title{
The Boundaries of Representation of Architecture and Art in Public Space, International Architecture Biennial
}

\author{
M. Ebru Erdonmez Dincer ${ }^{1}$, C. Abdi Guzer,"* \\ ${ }^{1}$ Faculty of Architecture, Y1ldız Technical University, Turkey \\ ${ }^{2}$ Faculty of Architecture, Middle East Technical University, Turkey
}

Received October 2, 2019; Revised November 22, 2019; Accepted November 25, 2019

Copyright $\odot 2020$ by authors, all rights reserved. Authors agree that this article remains permanently open access under the terms of the Creative Commons Attribution License 4.0 International License

\begin{abstract}
The physical environment generates myriad of values and comprises various connotations. These values and connotations, which are directly or indirectly represented by the output, generate a sampling area to understand the production and consumption forms of the physical environment, of its cultural, social and economic priorities and contextual relations. Therefore, architecture is utilized as a tool to understand the historical transformations and relations in various disciplinary fields while architectural criticism tries to understand the architectural building process and its outcome by exceeding its professional boundaries and observing the relationships between different disciplines and architectures. Literature, art, philosophy, politics are alternative means of expression, which complement architectural criticism. In this context, architectural biennials perform as periodical discussion platforms, which perform as an alternative space for the criticism and documentation of the current issues of architectural production and its most dire problems through a selection of works under a certain theme. The works exhibited at the biennial use different tools of narration in various disciplinary bases in addition to architecture itself, and therefore create an environment for generating content and values with multiple inputs for discussions as well as concepts defining the architectural outcome. In this paper, it aimed to discuss and evaluate the accumulation of works exhibited at the biennial with various contextual and conceptual arguments and interpretations, and the boundaries of functionalization of biennial exhibitions as a platform for architecture criticism.
\end{abstract}

Keywords Biennial, Architecture Biennial, Architectural Criticism, Public Space, Representation

\section{Introduction}

An architectural work is an object which is perceived by a large group of people inevitably not just limited to its users, effecting its immediate surroundings in various scales and forms, carrying a meaning for both itself and its context and embodying a representative and a signature value. In other words, an architectural work, in addition to its primary function, undertakes direct or indirect subtasks and beholds meanings that relate to a common public memory. It represents the historical, cultural, traditional, ideological and political priorities and reversely it allows for the retrospective reading of many historical, sociological and political phenomena through architecture. This additional function of architecture becomes especially important and prominent in urban areas and densely populated central zones. On the other hand, building up architecture with certain qualities and sustaining its existence is directly related to the expectations, priorities and cultural structure of the consumer society as much as the professionals who physically produce it. The presence, sharing and consumption manners of architecture in public spaces are important both for the cultural environment of architecture and the boundaries of influence and transformation of that environment over architecture. Architecture uses a variety of tools to expand the boundaries of this interaction. Certainly, the main tool is the built environment itself. However, the knowledge of architecture tries to express itself utilizing directly the cultural setting and means of communication by means of various publications, exhibitions and activities and also to functionalize a critical cultural environment within disciplinary relationships.

In recent years, architectural biennials stand out among these tools as their numbers gradually increase. Biennials, such as Venice, Sao Paolo, Rotterdam, Chicago, Seoul, Hong Kong, Shezhen by hosting exhibitions, events and temporary interventions on the public space, contribute to the development of a sustainable culture of critical thinking within the profession and also contribute to the development a culture of participation on debates concerning architectural and environmental issues for the 
inhabitants using these public spaces. Likewise, the International Architecture Biennial Antalya organized by The Chamber of Architecture of Turkey, Antalya Branch, is on its way to become institutionalized as it has already completed its fourth exhibition. In terms of both its schedule and content, the biennial shows similarities to other international biennials and also has its unique features.

The unique context of Antalya city and the relationship with the public space is what mainly sets it apart from its peers. Antalya combines the traditional and contemporary architectural texture tightly knit together, and this complex structure allows for an authentic contextual and sampling environment with its population gradually becoming more cosmopolitan. This authenticity is reflected in the works created for the International Architecture Biennial Antalya, especially the Experimental Architecture Works in public spaces create a basis for inquisitive, critical and instructional feedbacks regarding both the architectural output and their relationship with the urban context.

The works exhibited at biennials aim to have a connection with different groups of audiences via a problem, concept, research idea or an experimental work which is directly or indirectly related to the content and theme of the biennial. Therefore, the works exhibited at biennials not only make use and functionalize the hosting disciplinary field but also other fields which help convey the main message in a strong manner. Architecture biennials which make use of the built environment and the physical inputs effecting that environment in addition to other contextual inputs such as art to history or economy to culture as a venue, create a more inclusive and diverse environment for exhibition and can easily expand to different disciplinary fields. In spite of this extensive area of description, no matter what the background idea refers to, especially the main disciplinary field used for presentation and communication environment is art. In other words, biennial find its expressions on public space by functioning the methods and interpretations which are typical to art. That is to say, architecture biennial while making a statement on urbanism and architecture it also represents the intersection, continuity and conflict between art and architecture. Reversely, these statements made on urban areas presented to the city and audience, are not just limited to architecture but also contains an artistic expression.

This study aims to understand, to sample and to evaluate the experimental works presented at the International Architecture Biennial Antalya in relation to the urban context and public space and by means of discussing the boundaries of representative relationship between public space and architecture in order to understand the biennials as a critical platform. The study approaches to the examples selected from experimental works and installations in various zones of Antalya city with various urban fabric and variety of public characteristics. The influence and transformation ways of these examples has been experienced during the biennial and the boundaries of architecture related to creation of public space and usage has been questioned.

\section{Aims and Objectives of the Research}

This study aims to question an architectural theoretical knowledge within a platform for experimentation, to discuss the functionalization of the boundaries of architectural criticism in various disciplinary fields, language and means of expression beyond a theoretical environment. The positioning of the works and presentations exhibited in public environment in the sampled architectural biennials, resulted in presenting problems and ascertains related to architecture and urbanization in an indirect way of cultural evaluation and criticism. The examination and interpretation of these presentations allow the architectural criticism to take part in various disciplinary platforms using indirect forms of expressions, to understand its effect and boundaries and to evaluate. Instead of studying and discussing the titles among the various themes of the Biennial directly or within their own disciplinary fields, this study aims to measure the contribution of these titles as visually represented in public spaces and their usage in disciplinary fields as a form of criticism and knowledge. Rather than the social effect of these individual works, this article concentrates more into understanding the continuity between the discussion topic and visual representation and the highlighted conceptual background of these works. Likewise, the boundaries of other neighboring disciplines to architecture such as art to be used as a platform of architectural criticism are also discussed. The study in this sense carries the samples collected from the installations exhibited in the biennial into the arguments within architecture and urban research and with these arguments, questions the continuity between the abstract and visual expressions. The main purpose is to uncover the power of sustainability of the works in biennials, recognized rather as an artistic event in popular culture, via abstract and theoretical exercises and to discuss the boundaries of non-verbal architectural criticism to be executed in various disciplinary platforms.

\section{Biennials as a Criticism Platform}

The urban space represents integrity not just with its physical attributes but also with its social, sociological, and psychological aspects. In urban space, the streets and squares are organic parts of the society. Humanity since the antiquity needed these squares, gathering areas, common spaces in order to escape the turmoil of city life in all cultures, and to meet, discuss daily problems, relax and to rest.[1]

The technological, financial, social and cultural transformations that we live through, effect 
simultaneously the definition of public space and it transforms from being just a physical space into a media and digital environment shared by communication networks and free from its geographical attribute.[2] On the other hand, the urban and architectural identity standing out in the consumer society and considered as a marketing tool, develops a new public space that is first of all 'validated in diversity', context-free and unattached. For example, shopping malls popping up almost in every region, rather being just a commercial structure, appear to be alternative semi-public places.[3]

Furthermore, certain physical spaces that do not fall within the traditional definition of public space in terms of their size, dimension and structure typology, may obtain a public space character by sheer density of use and therefore interrupt the traditional representational relationship between architecture and public space. Due to new consumption behaviors, urban spaces become not just static physical locations but dynamic and receptive environments which can be re-defined by events. As a result, not just buildings but the flora, urban furniture, statues, events, installations become elements composing the public space and articulated with the structural infrastructure. Events such as exhibitions and biennials can be effective on this spatial transformation and re-definition process. The difference between the exhibitions, biennials and the traditional events is that they use the urban space as infrastructure and can initiate a process of criticism and transformation for that particular space.

The first architecture biennial organized in the world is the Venice Biennial in 1895. The earlier attempts of the Venice Architecture Biennial mainly focused on decorative arts and only in the first decade of the 20th century it gained an international scope. It can be observed that the international exhibition which began to take place from the year 1980 on began to look for understanding the impact field of architecture. Except for the first four exhibitions curated by Paolo Portoghesi and Aldo Rossi where the impact of the biennial on the international community of architects was not year entirely clear and beginning with the exhibition in 1991 when the national pavilions were first set up, there is a clear tendency towards conveying the audience more than architecture itself through main themes that refer to the city and the urban space with the help of rather stimulating and impactful contributions which put context and process to the forefront. This tendency became rather obvious especially throughout the exhibitions starting with the edition in the year 2000.[4]

The curator of the 14th exhibition on 2014, the internationally renowned architect Rem Koolhaas emphasizes this tendency and chooses to embrace the motto "Architecture, not Architects" in order to reduce the expectations from architecture and what it can refer to, but the will to focus on architecture itself. Koolhaas explains the processes and phenomena he would like to focus on with his claim "Without the balcony, the history of the world would have looked completely different", referring to many political breaking points in history where the balcony was a critical spatial tool in conveying a message to the masses. By labeling the theme of the exhibition "Fundamentals", he denotes his wish to utilize the biennale as a space for discussing architecture itself instead of a showroom for star architects and their products. The following exhibitions in 2016 and 2018, the Venice biennale again focuses on topics which focus that deal with the larger field of impact on the architectural discipline.[5]

The Rotterdam Architecture Biennial is another example which has also proved itself to be of significance although it certainly does not yet match the impact of its counterpart in Venice. Its ambition to mirror the topics dealt with at the Venice Architecture Biennial failed at most times due to the fact that its international scope was rather limited and the extents of the exhibition in terms of space and participation were restricted. The Rotterdam Biennale is now held only in every four years and struggles to create the impact it originally wished to achieve.

Within the same time period, the extensive structural development and property investment in Southeast Asia and the Emirates moved the focus away from European cities as the main stage for architects to prove their worth, which also moved the debate on architecture further east to these geographies. The exhibitions organized in Shenzhen, Hong Kong and Seul are clear demonstrators for this trend. At the same time, in addition to the architecture biennale held in Sao Paulo, the Chicago Architecture Biennial which began in 2017 managed to gain plentiful attraction.

Observing the selected themes and debates, it is possible to identify a political and philosophical attitude both in art and architecture biennials. Actually, the process is perceived as contradictory by most artists, and it is believed that globally biennials organized with the financial help of many international companies use art as an instrument to achieve their own goals. However, the most significant achievement of biennials thus far is the integration of art and architecture into the daily life of the city they are organized at and the fact that visitors can experience the works of many well-known artists and architects, follow the debates within the themes and participate during the biennial.

The architecture biennials should be considered as a critical platform, trying to understand the incidents within its professional area beyond the boundaries of singular representation of the work, creating alternative evaluation grounds by carrying the priorities in the selected themes to various other disciplinary arguments. So the works at the biennials aim to discuss the knowledge developed in other disciplinary fields by using the exhibition or expression 
forms in a disciplinary multiplicity and interpreted the architectural work multi-dimensionally.

Demetri Porphyrios defines the architectural discussion as "a form of representation ignoring some definitions for the purposes of the dominant power relations and legitimize the current situation".[6] In this respect, biennials and similar events should be considered as a ground of questioning the existing architectural discussion and generating alternative definitions and arguments for criticism processes.

Moreover, Tafuri underlines the problems arising from recognizing architecture just as a constructed environment and considering it only within its own disciplinary field and he emphasizes on the importance of looking into architecture from outside. Therefore, biennials create a platform to look into architecture from outside and just like Tafuri emphasizes, the architectural criticism, contributes to the efforts trying to eliminate the distinct boundaries between theory of architecture and history of architecture.[7]

\subsection{International Architecture Biennial Antalya} (IABA)

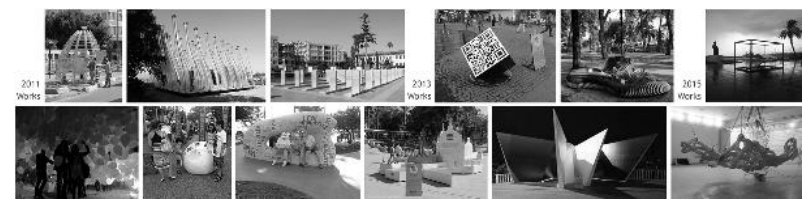

Figure 1. Experimental Architecture Works / IABA 2011, IABA 2013, IABA 2015

Currently in Turkey the architectural environment is far away from all these variety and wide range; the vision towards the city and architecture is defined on the scale of the individual work or what professional priorities define, the relations between architectural quality, philosophy and art is considered as a luxury currently out of discussion. Thereupon, The Chamber of Architecture of Turkey, Antalya Branch in 2001 came with the idea of organizing an Architectural Biennial in Turkey and realized the first International Architecture Biennial Antalya (IABA). The purpose was to reveal the approaches that contain some unique differences arising from the physical, cultural and traditional characteristics of this geography in use of public space.

In the same context, the first International Architecture Biennial Antalya was organized under the theme "Kesişmeler (Intersections)" the second one was themed as "Şablon (Pattern)", the third one was "Geleceği Düşünmek (Thinking of Future)" and the fourth one was themed as "Süreklilik (Continuity)" in order to strength of the relationship between art and architecture over the city and its inhabitants through exhibitions in public space. Moreover, the International Architecture Biennial Antalya not only brings forward a conceptual and theoretical approach to the architectural profession, but it also involves in architectural and spatial applications within "Experimental Architecture Works" concept and contributes to the profession by generating a platform for the bringing up new architectural arguments. The ultimate goal for the International Architecture Biennial Antalya is for it to become a clear part of the urban culture by providing a platform to initiate discussions on architecture and the city through experimental works by architects as individuals or groups with contributions from all related disciplines, exhibited at critical spots within the city that interact with the place.

"Most of the installations which become part of the daily routine or part the context they are located in, allowed for the urban space and the architectural works related to it consumed daily and habitually by users or audience, to be perceived in a fresh and different manner and create alternative relationships with them. Another important observation is that almost all of the outcome was built in a qualified and well thought manner within international standards from content generation to construction. When considered as a whole, as a result of architecture and the natural effects of daily culture emerging from consumption behaviors in the city, we are alienated to many facts in the city which accepted as value and so we observe an effort to question our way of living, the consumption of the city and to create alternative perceptions and awareness".[8]

As an important part the Biennial, the "Experimental Architecture Works" strongly interfaces with the city and its inhabitants include installations which particularly emphasize the philosophical, artistic, cultural and critical qualities of the architecture. The building process in experimental architecture exceeding the traditional forms of understanding focuses on spatial practices by developing a vision which questions the systematics of existing rules and plans. This is actually where the design creates its own content. Although the aim of these rules and sequences is to ease our lives, this situation provides an opportunity or even sometimes a need for designers to see out of the box.[9]

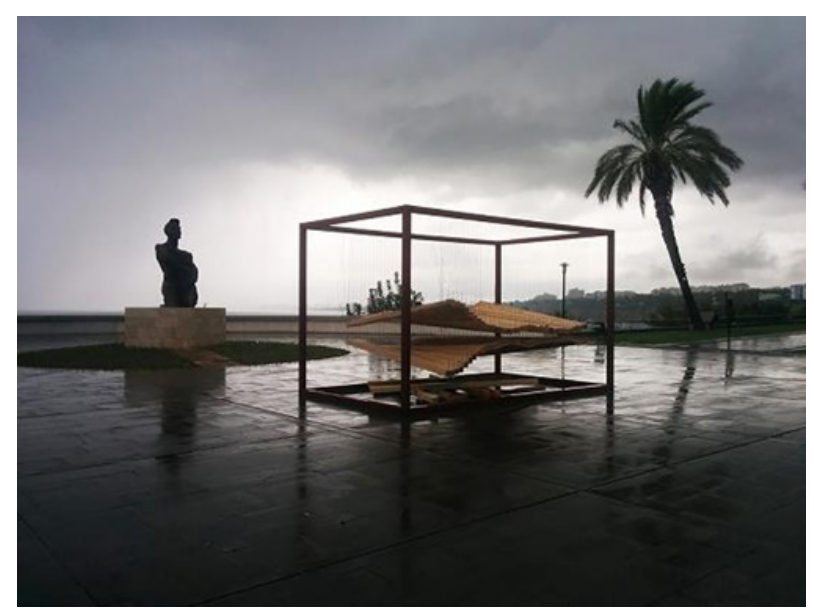

Figure 2. Alisan Cirakoglu, Experimental Architecture Works / IABA 2015 (Photo: A. Cirakoglu) 
Being experimental requires building new forms as well as analyzing issues from a fresh perspective. Nonetheless, during experimental works, the spatial examination, configuration and a user experience that evolves beyond the control of the architect/designer create diversified judgments. The aim in these works is to make the act of practicing architecture become tangible within public space, and to have the profession recognized transparently and experimentally through temporary spaces.

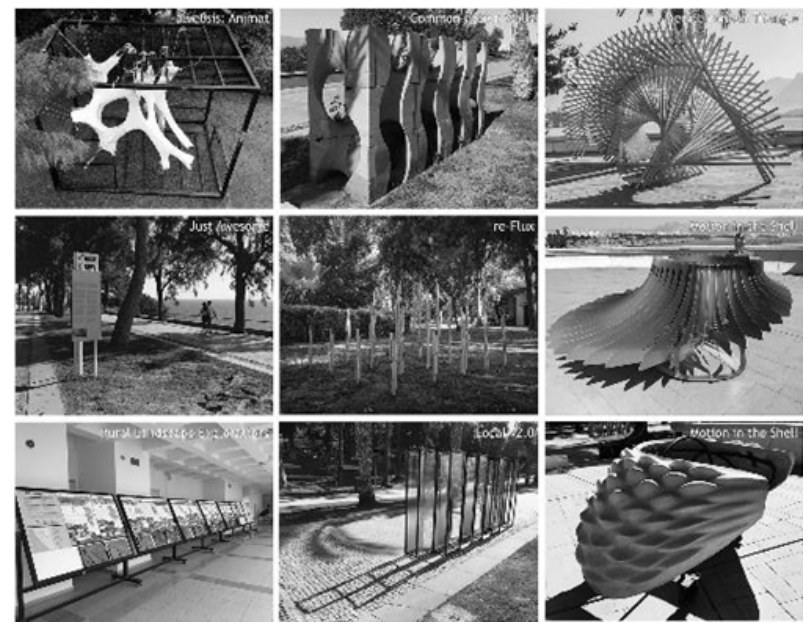

Figure 3. Experimental Architecture Works / IABA 2017

\section{International Architecture Biennial Antalya as a Criticism Process: Understanding Architecture and Urban Relations through Experimental Architecture Works}

In order to illustrate the discussion within the scope of this study, the 'Experimental Architecture Works' section, which constitute the main axis and the base for interpretation of the International Architecture Biennial Antalya, are being discussed. While staying within the main theme of the biennial, the differentiations in the relationship of these works with the theme and the city depending on the comments and expression techniques of the artists are open for evaluation in platforms with different priorities and discussions. Accordingly, architectural criticism tries to evaluate the styles of the architectural work and the physical environment to be shaped under the influence of multiple inputs and the representational relationship of these inputs with the physical environment.

The example works chosen here were analyzed in subchapters following the biennial themes and representing the issues that exist within the architectural discourse. Additionally, they were evaluated by the discussion topics according to their forms of feedback. Obviously, these installations within their richness of concept and definition forms are open to be related to many subtitles and discussion frames. The main target is to sample these installations in the form of relating to biennial theme, rather than just understanding within their richness of definition. The installations should be considered as public use and open to various effects and inquiries, and they have to be comprehended. This study focuses on their expressions on contextual continuity / conflict, awareness, belonging and identity, cultural representation / daily life, symbolic value, and critical representations that are developed via discussions within the main theme and the entire biennial. From this point of view, it would be possible to consider the biennial installations being more than just independent artistic activities but also as part of a critical process, a form of definition related to different disciplinary fields.

\subsection{Contextual Continuity / Conflict}

International Architecture Biennial Antalya, as an input to its authentic physical, climatic, traditional and historical structure, has used a significant part of the experimental installations to question the contextual relationships or means of representation. Almost all of the biennial themes developed over the years are the basis for discussing problems related to the contextual relations observed in the physical urban texture. The fast urbanization process in Turkey and the typical construction styles of the global culture that we are part of, cast out the authentic architectural understanding which relates to land in a multi-dimensional way. The concept of "placelessness" constitutes the dominant face of cities. The concept of "critical regionalism" which was emphasized by Frampton for a contextual and land sensitive architectural view has become the starting point of most of the presentations and works.[10] For this reason, a part of the installations is composed of samples which relate directly with their surroundings or spend effort to transform and redefine it. 


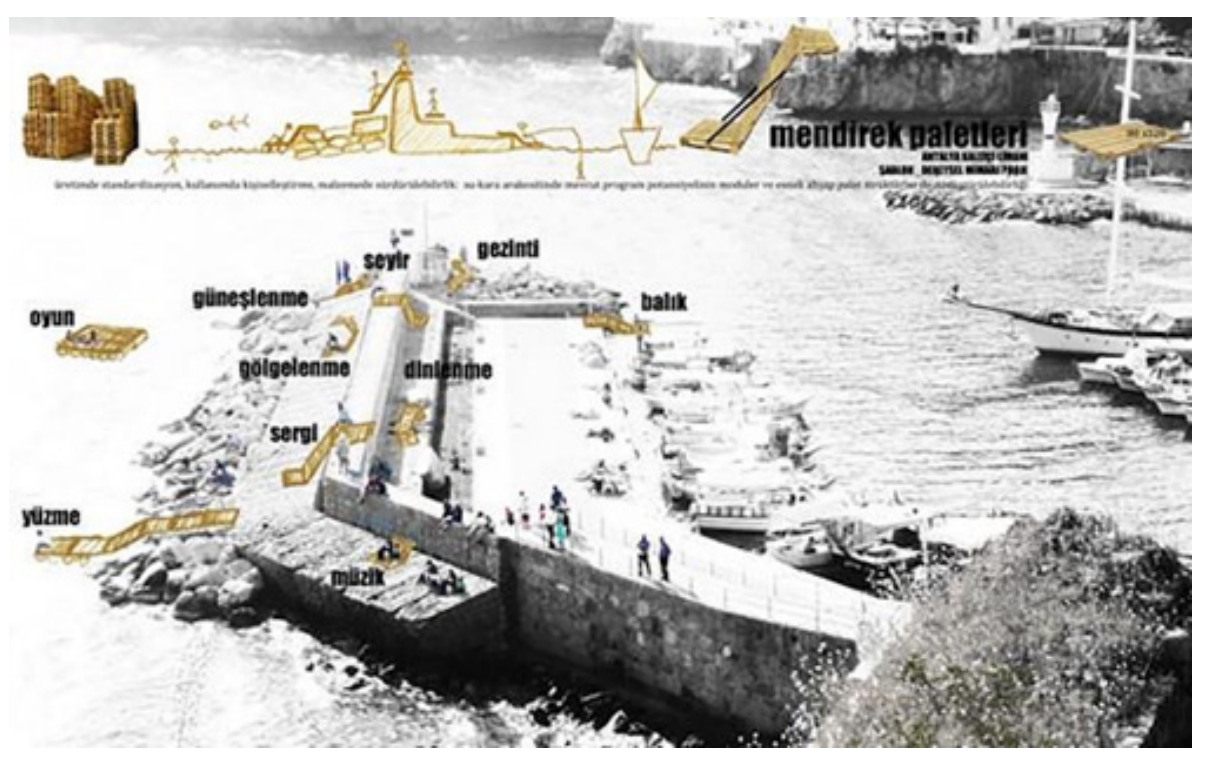

Figure 4. Palettes of Jetty, Defne Onen, Experimental Architecture Works / IABA 2015

The "Palettes of Jetty" created by Defne Onen can be considered within these examples. This work aims to question the recognition of construction, space, object, material, public space patterns. The logistics euro-palette which essentially designed for standardization has been carried alongside the jetty of Antalya Kaleici to create an alternative field and representation on existing environment. In a way, the work gets its meaning through the relationship built between location and the context and transforms its context by building coherence with it.

The area where the installation is located has lost its historical function of being a shipping port, industrial and commercial area and socio-economically been transformed into a touristic area instead. Within this transformation the palette material, which is in fact not foreign to this zone, is redefined by carrying a new function for consumption of the area. The architect Defne Onen describes the work as "a range of indoor-outdoor spaces, defined by the walls of the jetty, with a view towards the city, to old town harbor, and away from the city, to the sea and Taurus mountain range beyond".

The installation composed of a range of lightweight structure, emphasizes, simplifies, interprets and diversifies the social behavior habits existing on densely populated pedestrian routes. The palettes while constitute relations between different elevations, inhabitants, land and sea they also contribute to the relationship between body and space and offer new functions related to the dynamics of space for its users. The spatial experience created by the installation, which is in continuous relationship with the context, strengthens the meaning of the context and also transforms it within its own dynamics. Placelessness, and to re-function a material used for displacement to establish a relevance with the location, has a direct contribution to architectural discussions of location and context.

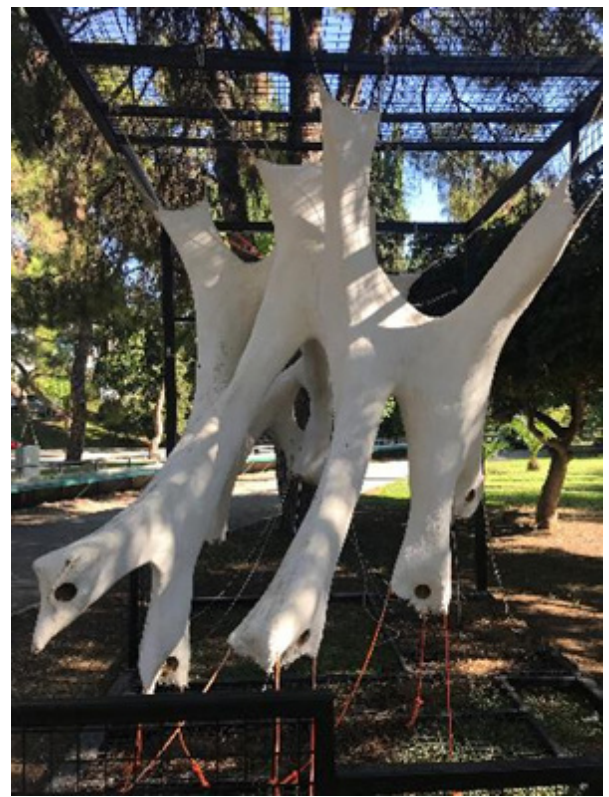

Figure 5. Alveosis, Nilufer Kozikoglu \& Urban Atolye - Experimental Architecture Works / IABA 2017 (Photo: Erdönmez, M. E.)

Alveosis is an experimental work carried out by Urban Atolye, which was established by Nilufer Kozikoglu as a result of her works on material- and structure related research and design. Alveosis is an installation in Karalioglu Park resembling the bones of a giant creature or a giant root. It is a tubular network of branches with holes and contains a living organism in its holes. Alve means 'with holes and cellular' and is a derivative of the word alveolar. Alveosis emphasizes the formation of phases of cellular structure. Being a part of the Nilufer Kozikoglu's material and structure research with the name Alve, the work is created by spraying concrete with added fiber on fabric mold with the support of Fibrobeton. 
Besides the structural attributes of the installation with its cavitied and continuous network, the design includes mushroom seeds mixed with wood shavings stuffed into the structure. It provides an opportunity to observe how the structure would react or harmonize with the other organisms surrounding or interacting with it. The designer presents to its architectural audience, a research summarized as biophilic design where the organic and nonorganic can commonly exist in continuity. It has been observed that the design transforms the location it interacts with and also re-defines it with its own existence.

\subsection{Awareness}

Within the process of urbanism, together with the definition of "placelessness", another often discussed term "alienation" means the loss of the mental continuity relation established with the land. Bauman defines the concept of "alien" in social life as being physically near but mentally distant.[11] Within the post-modern culture, we have difficulties in establishing a critical and semantic relationship with many urban phenomena that we are physically related to. Especially the consumer society culture aims to approach our environment in reduced and uniform classifications and to liquidate their exclusive diversity. Antalya and especially the biennial district, has many authentic and multi-defined physical settlements together in historical layers. Within the daily flow and restrictions of social culture, we cannot establish a reasonable awareness relation with most of the elements in this environment. As Bauman states, we cannot carry our physical proximity to mental dimension. A part of the works in the International Architecture Biennial Antalya, aim to carry the physical and visual relationship established with the city to an awareness process and in a way to create a critical perception.

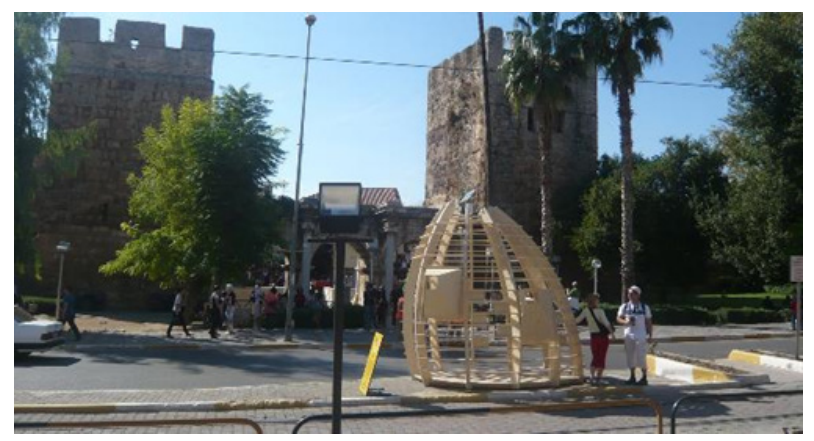

Figure 6. Bakanak, Bogachan Dundaralp, Experimental Architecture Works / IABA 2011 (Photo: Erdönmez, M. E.)

The "Bakanak" installation in Experimental Architecture Works, located at an axis with an intersection of different historical layers. The installation, which was located at the central refuge on the road between the Gate of Hadrianus and the Karakas Mosque, guides the visitors to observe the surrounding buildings explicitly once inside.
In this respect, the design creates awareness towards its location and the city, and establishes a physical and visual relationship. The climatic conditions effected the selection of the material; the natural wood was used to attract the attention to the fact that wood is not sufficiently used although expected to be so considering the climatic conditions of Antalya. The main purpose of this installation is to create awareness by attracting attention to selected multi-layered focus points that city has generated and again create a sense of belonging with the individual meanings of the elements.

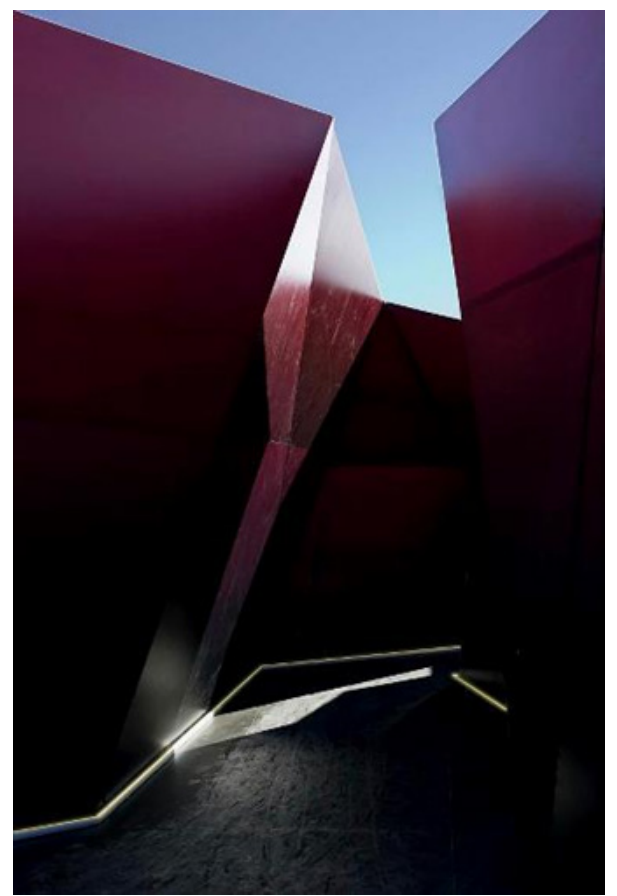

Figure 7. Intersect, Fikret Sungay, Salih Kucuktuna, Guvenc Topcuoglu - Experimental Architecture Works / IABA 2011

The "Intersect" project located in public space belongs to Fikret Sungay, Salih Kucuktuna and Guvenc Topcuoglu. As a starting point for the design they considered the interaction of architecture with the people living in and got inspired by the organic/dynamic pattern of the Antalya Old town district, which was formed by the social life, traditional architecture, history, climate, geography, multi-cultural structures and many other parameters. The project provides an impression of an Old town street, gained significance with the axis created, as a tectonic structure and typology, the dynamic structure in its geometry, its material, all intersect in a triangle of modern life, existing organic historical street structure and human perception.

\subsection{Belonging and Identity}

Although globalization redefines the physical environment in the modern society through production and consumption processes, social life forms are 
becoming independent from geographical differences. This tendency enforces uniformity which in turn deteriorates the feeling of belonging and the intimate relationship of person to a place, and the values of identity established with culture through place. David Harvey defines post-modernism as "the cultural logic of late capitalism" and emphasizes the standardization effect of the new flexible production processes against the geographies.[12]

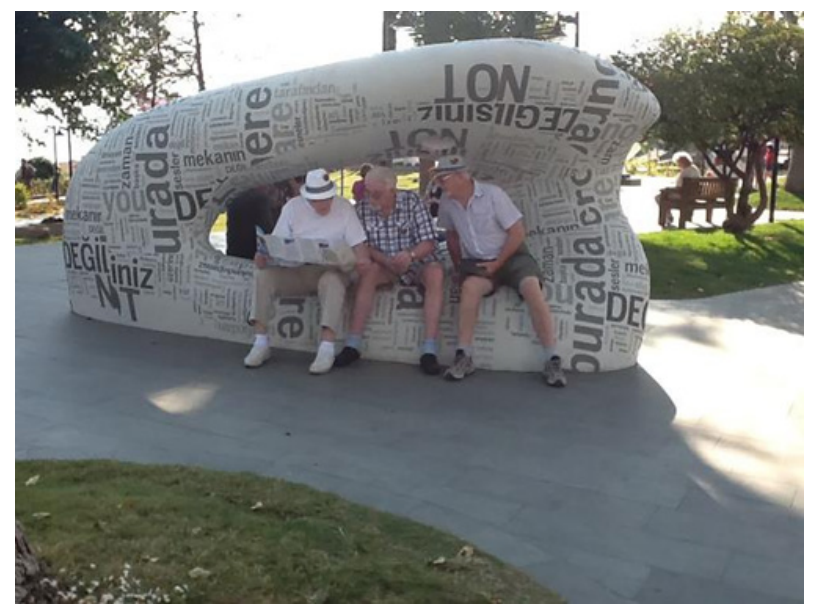

Figure 8. Not Here, Ahmet Onder, Ceren Balkir - Experimental Architecture Works / IABA 2011 (Photo: Erdönmez, M. E.)

The work exhibited at the biennial with the title "Not Here" aims to recreate identity through an installation that is not only foreign to its location in the city but also to the typology of urban furniture around itself. Its serves as a pit stop which establishes a specific relationship that place and a sense of belonging between the user and the place. The work was installed within a crowded pedestrian zone in the city, as a standalone element within a foreign morphology.

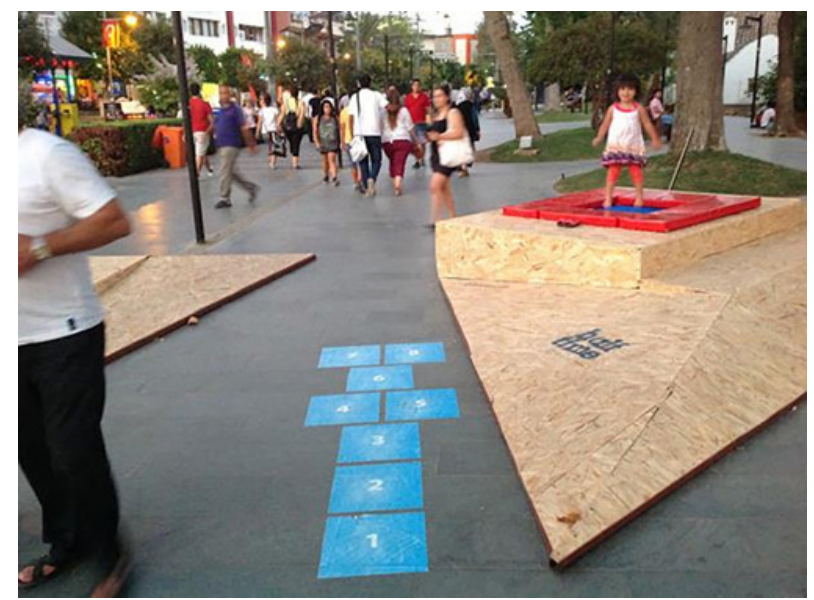

Figure 9. Half-time, Cengizhan Aydin, Tugce Sahin - Experimental Architecture Works / IABA 2011 (Photo: Erdönmez, M. E.)

The city and especially the public space have always been a place where inhabitants from various cultural backgrounds can meet. It is an urban space for individual and group activities bound by commonly accepted rules and reflecting the needs of its users. In the work "Half-Time", the designers aim to observe the physical environment by disconnecting form the place, its habitual and known context, to re-route the conventional usage of the location and so establish a belonging feeling between the place and the individuals. The design offers the possibility to spend time on the pavement, to stop, to play and to have fun rather than just to walk or pass by.

\subsection{Cultural Representation / Daily Life}

Every object in the built environment has a representation value together with its functional value, and the physical environment is associated with everyday life in various scales, densities and priorities. Jean Baudrillard mentions that a post-modern world emerges within in pop-cultural environment with the effect of media and choices of the consumer society, where everything is reduced to "representations".[13] In daily life the relationship we establish with city and space finds meaning and value mostly from this reduced representation whereas the awareness and originality that the critical culture may create are usually hidden. In most of the experimental works at the Biennial, it is possible to observe an effort to transform this reduced representation value to a critical awareness.

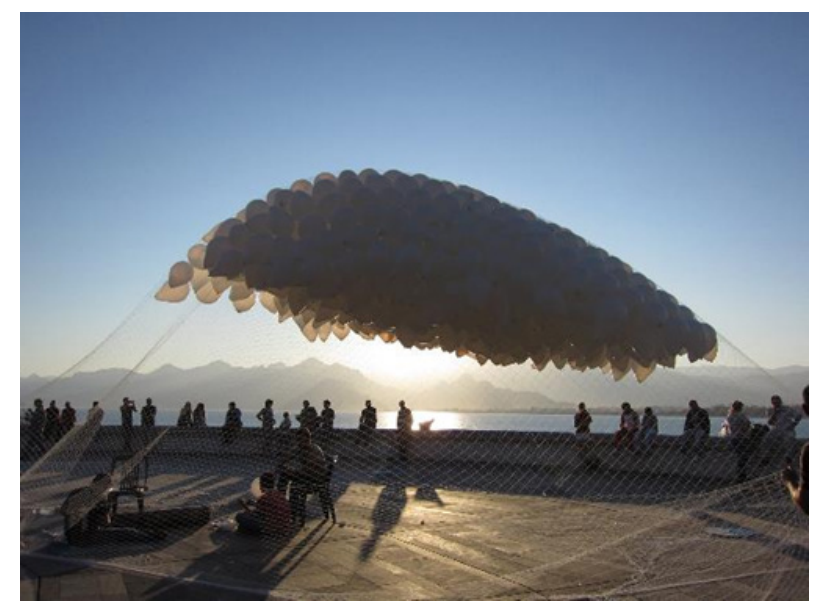

Figure 10. Anti-gravity, Ebru Erdönmez, Burak Haznedar Experimental Architecture Works / IABA 2011 (Photo: Erdönmez, M. E.)

The project "Anti-Gravity" aims to define the way of designing a space or a form without gravity create volumes that cannot exist in everyday situations, with the help of easily found casual objects. The layers of the volume and its space as an emptiness by creating intersections of before and after's, piling up the elements within this association, carrying it away from its daily meaning and establishing new forms. The work created by generic tools like balloons and a net, provides an opportunity to re-constitute spatial relationships in a dynamic way, each time with a new user. This unusual and dynamic space questions the perception of daily 
'admitted' spatial representation and habits.

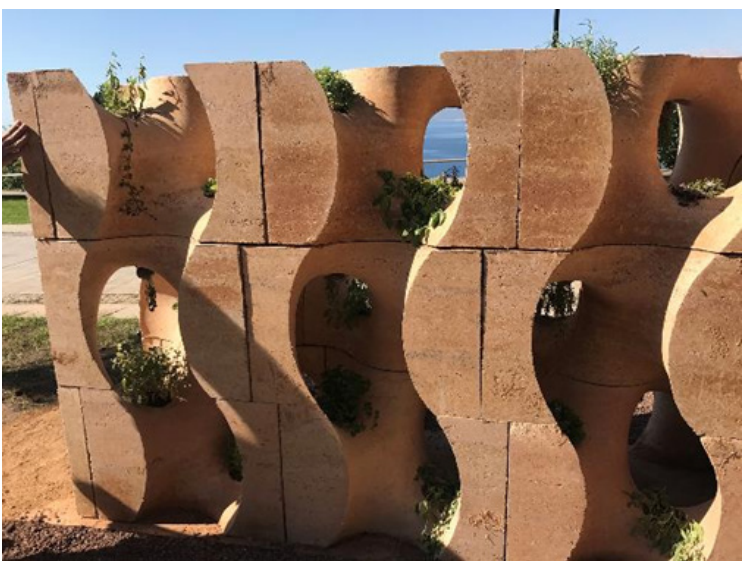

Figure 11. Common-action Walls, POT+, Fulya Ozsel Akipek, Tugrul Yazar, a.o. - Experimental Architecture Works / IABA 2017 (Photo: Erdönmez, M. E.)

Likewise, in the project "POT +" uses two separate elements together carrying static representation values in modern life; a wall and vegetation. The wall hosts plants through the holes that provide space to cultivate vegetables. "POT + " is the structure of cultivation, nursing and harvesting plants continuously, sustainability and works as a participatory urban garden idea. The team investigates forms and materials before the construction phase and by modelling the Gyroid network in a digital environment which provides the water flow from fluidal surfaces of the wall, they created maximum light and air flow and space for the plants. Supplementary elements such as lime and acrylic mixed, compressed and shaped with traditional soil and so the limits of its usage in daily city life was questioned. This experimental installation sends a message to environmental sensitivity while opening the representative values of habitual elements to discussion.

\subsection{Symbolic Value}

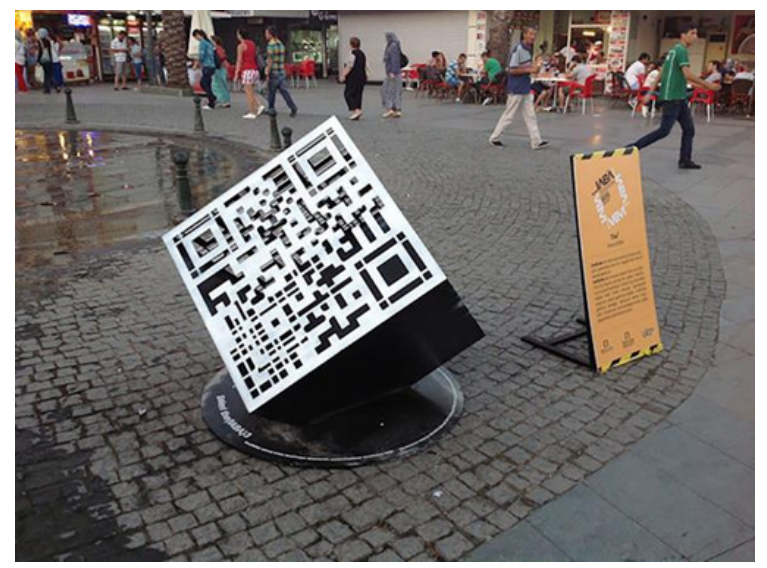

Figure 12. The Cube, Ekmel Ertan - Experimental Architecture Works / IABA 2013 (Photo: Erdönmez, M. E.)
Likewise, Baudrillard emphasizes the importance of symbolic value in consumer society culture and underlines the market value through from the symbolic values of objects. In modern urban environment, all objects, particularly the buildings, besides their functional values gain meaning with their symbolic values and even sometimes these meanings go ahead of their functional values.[14]

The Project "The Cube" is a public art project, a statue and a virtual gallery. Using a conceptually reversed (inside-out) metaphor gallery, the cube is a symbol representing the project itself. The codes at three sides of the cube connect the audience via smart phones to a virtual gallery and become the symbol of the gallery at the street.

The virtual gallery establishes an online network via cubes located in various cities of the world. Each cube takes the audience to different rooms of the virtual gallery. The (TODAYSART) 3 takes the audience to the virtual halls of TodaysArt Festival in Lahey and the (ISSYK-KUL) 3 to the halls of Bishkek Contemporary Art Center. It also takes the audience coming from The Hague and Bishkek to the halls of Antalya Biennial. The audience has to carry a mobile phone in order to view the work of arts in virtual gallery that the Cube is connected to. When they take a picture with a free application to read a QR-code they reach to the connected halls of the gallery and can watch or listen the works exhibited. In time, the cube transforms into an urban symbol representing art.

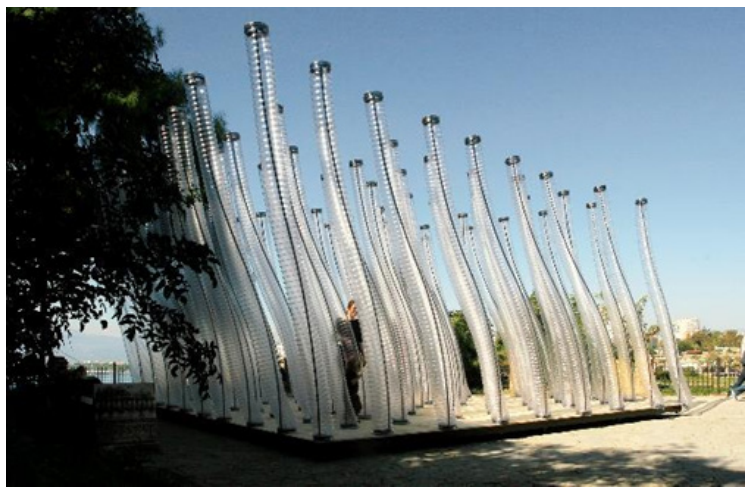

Figure 13. Sea ${ }^{3}$, Alisan Cirakoglu - Experimental Architecture Works / IABA 2011 (Photo: Erdönmez, M. E.)

The project of Alisan Cirakoglu; "The Sea3", interprets the concept of fullness - empty, one of the main topics of architecture, on the basis of the relation of Antalya with water. Installing the work in an empty space, the architect created gaps that people can fit in and thus desired to establish a physical relationship between people, architecture and biennial. As a result, we see that besides offering an abstract discussion and a landmark, the place itself becomes a symbol that can be redefined.

\subsection{Critical Representation}

The experimental works taking place in this study 
involve a complexity open to be understood and evaluated in a variety of references. The common platform in which all these samples gather is the critical representation value they involve in various perspectives. It is an effort to observe the incidents around us, by providing reference to the city, the physical and natural environment, as well as various discussion frameworks from a critical distance and to re-define them all. Some examples use the language and tools of art intensively and some others prefer to stay in conceptual frames where the audience is pulled in. In spite of all these differences, it is possible to read the biennial installations as a critical text and observe the transmissivity between the dissimilarities of cultural platforms as a definition on architectural criticism.[8] Most of the works carry characteristics of an art object involved in daily life and also represent discussion or parallel values which can only be gained through know-how and effort. In this sense, it targets daily users and also various disciplinary studies and references. Similarly, like Benjamin underlines, in the post-modern era, the objective production and the intellectual production establishing its background, are joined and the art piece performs a critical functionality. [15]

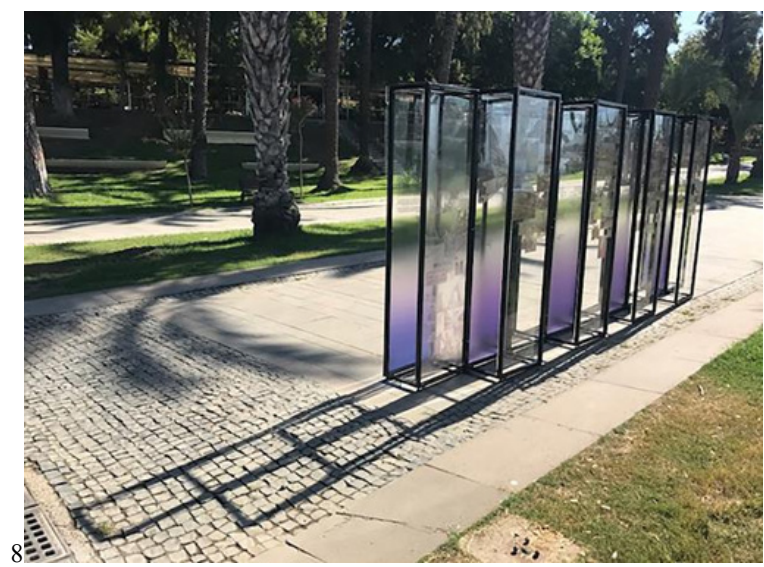

Figure 14. Local 2.0, Selcuk Kismir, N. Gokce Tufekci - Experimental Architecture Works / IABA 2017 (Photo: Erdönmez, M. E.)

Some of the works present relatively open and critically direct texts actually bring topics, concepts and researches that are not commonly discussed an everyday life into the daily life and to public space. The project "Local 2.0", examines the concept of sustainability which was generated by the economic, political and cultural transformation after 1980's. In this sense, the research aims to present a detailed matrix which analyses the actors and elements integrated into a construction in anywhere in the world, and to the process of establishment of that construction. While revealing the global designer, contractor and supplier network which create a single construction, referring to the same players and holding the traditional sub-locals at the background, it provides an opportunity for a double-sided reading.

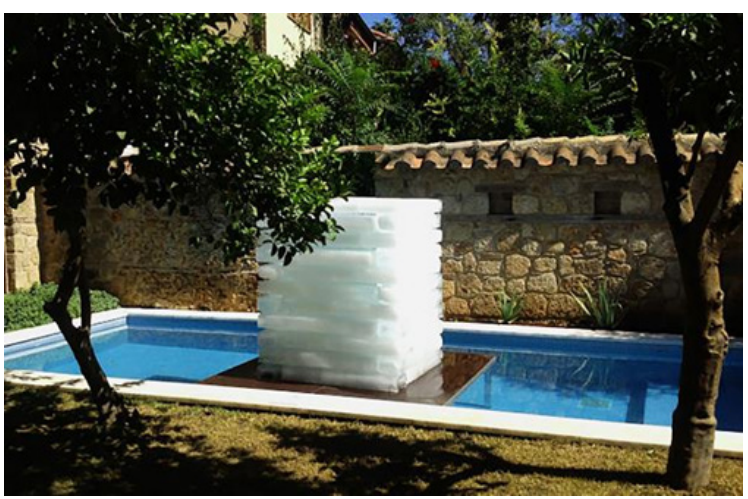

Figure 15. Between the Walls, Ferhat Hacialibeyoglu / IABA 2013

The "Four Walls" project which forces to think the concept of template itself, with a critical approach, underlines the question of how the form and design becomes a compulsorily template.

Table 1. Experimental Architecture Works

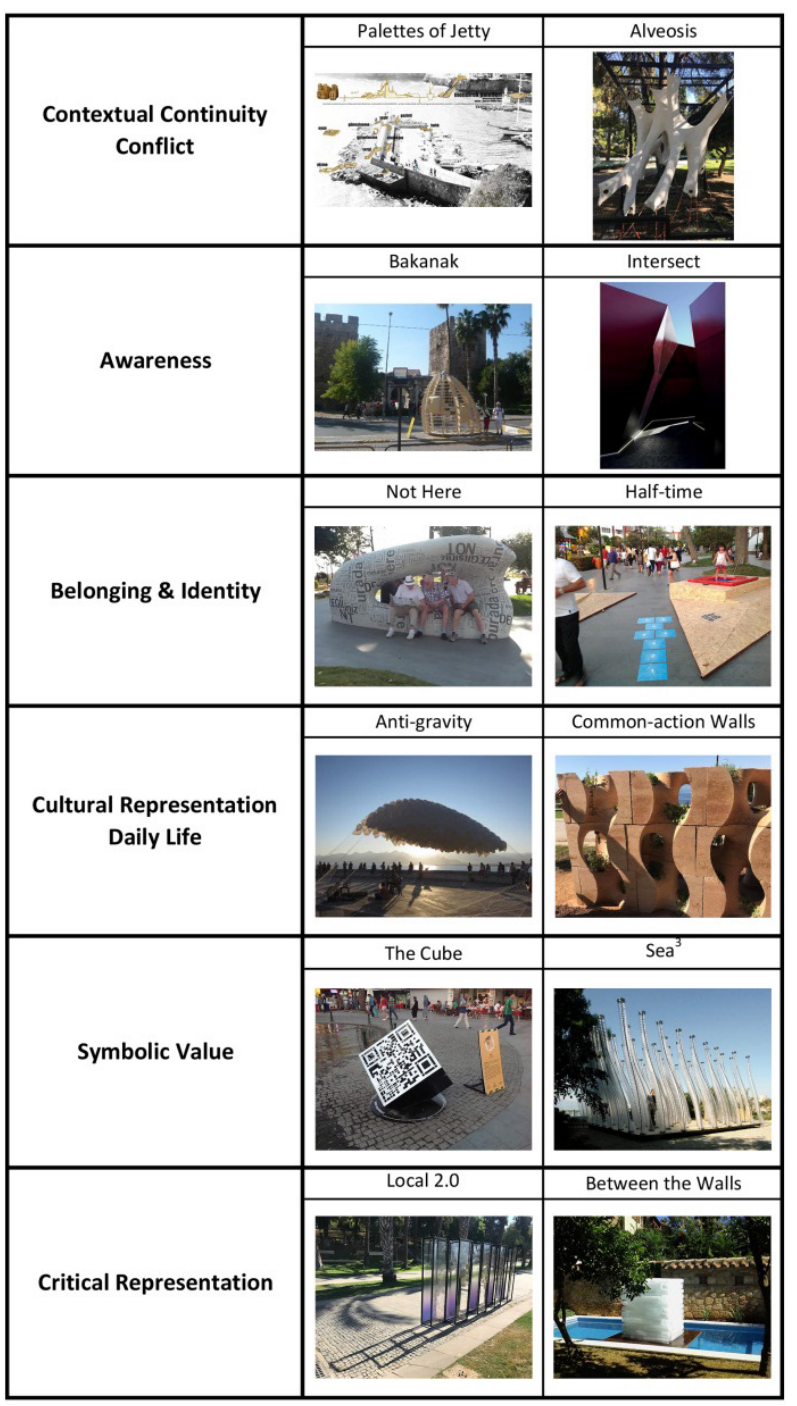




\section{Conclusions and Arguments}

This study discusses two fields within a relationship. First, biennials as a cultural platform for criticism, is more specifically the relationship between the architecture biennials and architectural criticism. Second, the representation forms and boundaries of the architectural culture and criticism especially in artistic and other disciplinary expressions.

In general, biennials, especially the architecture biennials, besides their interpretations of extensive activity have to be perceived as an alternative criticism environment, a critical process. The works in the International Architecture Biennial Antalya sampled in this research question perception and problems directly related to architecture and city within frameworks defined by modern day architecture problems and also provide a critical view to these problems not just limited to disciplinary boundaries. This approach which is especially discussed over Experimental Architecture Works functionalizes various disciplinary content and demonstration. The biennial exhibitions not only emphasize problems that we are accustomed to within the city and not aware of in daily life, they also represent an effort to reflect these problems to inhabitants and create awareness. Architecture when perceived in various other fields than its own profession; such as culture, politics, sociology, economy, history and art and when opened to discussion through alternative ways of expression which involve the presentation styles of these fields, the representation environment of the current power relationships and being more than a legitimization process, can be opened to new awareness and establish a real critical platform. Biennials in this respect should be considered as an alternative to inured forms of value generation and be perceived as critical platforms questioning and trying to reverse the legitimization processes.

The city is a collection of multi-layered relationships and the sustainability of the urban idea can only be possible by the participation of all players represented within these relations. Another contribution of the biennials is that they carry a potential of creating awareness by attracting a critical process not only by the certified actors in creation of architecture or art but also the other actors who also claim the space.

Considering all these observations, the International Architecture Biennial Antalya tries to actualize an alternative awareness mechanism for Turkey where especially the urbanism problems accelerate to become more serious and also tries to include the local inhabitants and the actors consuming the physical space into a critical process. One of the originalities of the International Architecture Biennial Antalya is the effort to relocate the exhibitions into public spaces and the sustainability relationship established with the city and its context. Like in many artistic work or biennials we should not expect a direct, solid, practical reflection and result from this example.

However in societies especially where the critical culture is missing and the architectural and urban criticism has not been institutionalized yet, the existence of these kind of critical platforms and to sustain them becomes vital. The biennial know-how introduces a rich data open to evaluation for various frames and new works. All these works directly or indirectly will contribute to the establishment of a critical architectural culture.

The argument, in which the study forms an experimental framework with examples and concentrates in more detail, emphasizes the continuity between art and architecture. In most of the examples discussed here, the installations with highlighted visual effects are in the form of an abstract critical expression. These expressions when perceived in continuity with the contextual architectural arguments, in parallel to their visual presentations, are a critical text open to various interpretations. It is obvious that in daily life with different users involved, one cannot expect these works which are associated with biennial theme and architectural discussions, to be perceived in the same way of representation, reference and clarity. it is not the direct aim of the biennials and the installations or exhibitions they hold, to create a representation which competes to texts or academic lectures generated in disciplinary communities. The biennials especially like the International Architecture Biennial Antalya which infiltrate into daily life and to urban areas aim to create awareness towards the physical environment and to urge some questions to be asked rather than to make a direct critical evaluation for everyday consumers. However, the biennials should be considered as a sustainable argument and evaluation environment regardless to its own product and exhibition period. In this respect these kinds of similar studies should rephrase the biennial exhibitions in disciplinary frame either individually or as a whole.

\section{REFERENCES}

[1] J. Habermas, Kamusalligin Yapisal Donusumu, Istanbul, İletisim Yayinlari, 2002; and, Walter Benjamin, Illuminations: Essays and Reflections, ed. Hannah Arendt, New York, Schocken Books, 2013.

[2] J. Habermas, Kamusal Alan, Istanbul, Hil Yayin, 2004.

[3] R. Trancik, Finding Lost Space: Theories of Urban Design, New York, Van Nostrand Reinhold Company, 1986; and, J. N. Okundaye, C. Gray, L. B. Gray, Reimaging Field Instruction from a Spiritually Sensitive Perspective: An Alternative Approach, Social Work, Vol.44, Issue.4, 1 July 1999.

[4] D. Chipperfield, K. Long, S. Bose, Common Ground: A Critical Reader, Venice, Marsilio, 2012; Online available from www.labiennale.org 
[5] R. Koolhaas, Fundamentals: Architecture, Not Architects, Fundamentals Catalogue; 14. Mostra Internazionale Di Architetture; Venice, Marsilio, 2014; Online available from www.theguardian.com/artanddesign/architecture-desi gn-blog/2014/mar/12/rem-koolhaas-venice-biennale-archit ecture

[6] D. Porphyrios, Building \& Rational Architecture, Architectural Design Profile, St Martins Pr; 1st English Edition, 1985.

[7] M. Tafuri, Theories and History of Architecture, New York, Harper \& Row, 1980.

[8] C. A. Güzer, Bir Kültürel Çatısma Alanı Olarak Mimarlık: Küresel Ve Yerel Süreklilik, 80. Yilında Cumhuriyetin Turkiye Kültürü, ed. Cana Bilsel, Ankara, Sanart Kongre Kitab1, Sanart Dernegi Yayınları, 2006.

[9] M. E. Erdönmez, Şablonun Deneyselleri, XXI Mimarlık Tasarım Mekan Dergisi, S: 6-10, Say1: 123, Ekim, 2013.

[10] K. Frampton, "Towards A Critical Regionalism: Six Points for An Architecture of Resistance", The Anti-Aesthetic Essays in Post-Modern Culture, ed. Ha Foster, Port Townsend, Bay Press, 1989.

[11] Z. Bauman, Postmodernlik ve Hosnutsuzluklari, Istanbul, Ayrinti Yayinlari, 2000.

[12] D. Harvey, The Condition of Postmodernity, Oxford, Basil Blackwell Ltd, 1990.

[13] J. Baudrillard, For a Critique of the Political Economy of the Sign, St. Louis, Telos, 1981.

[14] J. Baudrillard, "The Ecstasy of Communication", The Anti-Aesthetic Essays in Post-Modern Culture, ed. Hal Foster, Port Townsend, Bay Press, 1989.

[15] W. Benjamin, "The Author as Producer", Art after Modernism: Rethinking Representation, ed. Brian Wallis, New York, the New Museum of Contemporary Art, 1991. 